Correction

\title{
Correction: Pham et al. Bolt-Loosening Monitoring Framework Using an Image-Based Deep Learning and Graphical Model. Sensors 2020, 20, 3382
}

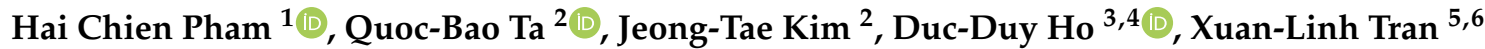 \\ and Thanh-Canh Huynh 5,6,*iD
}

check for updates

Citation: Pham, H.C.; Ta, Q.-B.; Kim, J.-T.; Ho, D.-D.; Tran, X.-L.; Huynh, T.-C. Correction: Pham et al. Bolt-Loosening Monitoring Framework Using an Image-Based Deep Learning and Graphical Model. Sensors 2020, 20, 3382. Sensors 2021, 21, 5280. https://doi.org/10.3390/ s21165280

Received: 10 June 2021

Accepted: 26 July 2021

Published: 5 August 2021

Publisher's Note: MDPI stays neutral with regard to jurisdictional claims in published maps and institutional affiliations.

Copyright: (C) 2021 by the authors Licensee MDPI, Basel, Switzerland. This article is an open access article distributed under the terms and conditions of the Creative Commons Attribution (CC BY) license (https:/ / creativecommons.org/licenses/by/ $4.0 /)$.
1 Applied Computational Civil and Structural Engineering Research Group, Faculty of Civil Engineering, Ton Duc Thang University, Ho Chi Minh City 700000, Vietnam; phamhaichien@tdtu.edu.vn

2 Ocean Engineering Department, Pukyong National University, Busan 48513, Korea; qb.tabao@gmail.com (Q.-B.T.); idis@pknu.ac.kr (J.-T.K.)

3 Faculty of Civil Engineering, Ho Chi Minh City University of Technology (HCMUT), Ho Chi Minh City 700000, Vietnam; hoducduy@hcmut.edu.vn

4 Vietnam National University, Ho Chi Minh City 700000, Vietnam

5 Faculty of Civil Engineering, Duy Tan University, Danang 550000, Vietnam; tranxuanlinh@dtu.edu.vn

6 Center for Construction, Mechanics and Materials, Institute of Research and Development, Duy Tan University, Danang 550000, Vietnam

* Correspondence: huynhthanhcanh@duytan.edu.vn; Tel.: +84-90-568-5633

The authors wish to make the following correction to this paper [1].

Figure 13b should be replaced by the following picture:

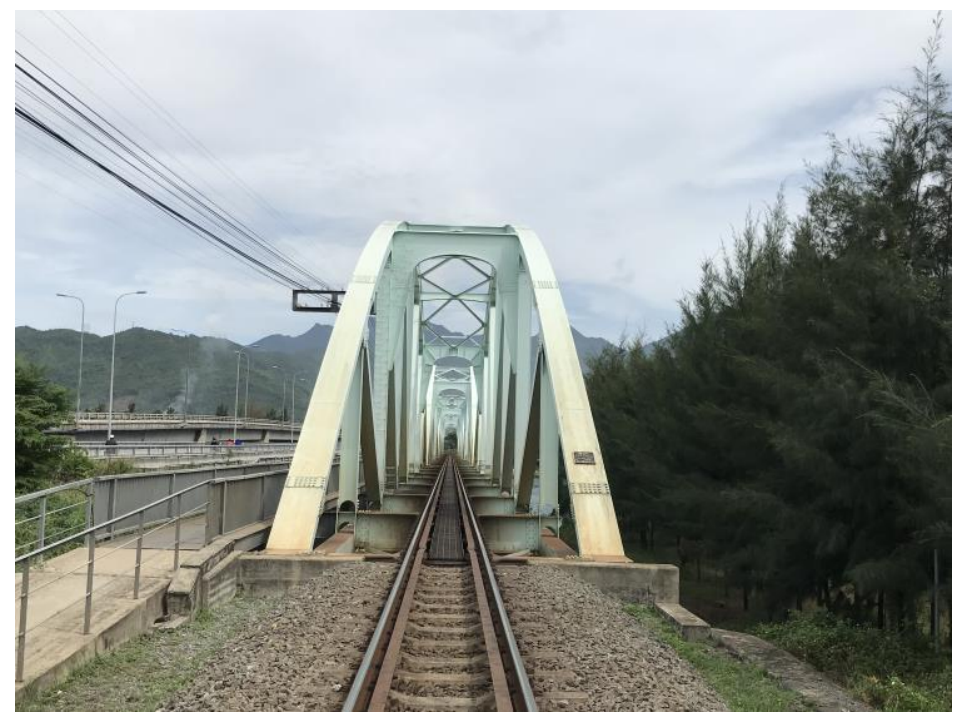

The authors apologize for any inconvenience caused and state that the scientific conclusions are unaffected. The original article has been updated.

\section{Reference}

1. Pham, H.C.; Ta, Q.-B.; Kim, J.-T.; Ho, D.-D.; Tran, X.-L.; Huynh, T.-C. Bolt-Loosening Monitoring Framework Using an Image-Based Deep Learning and Graphical Model. Sensors 2020, 20, 3382. [CrossRef] [PubMed] 